\title{
The Origins of a Healthcare e-Booking System in the Municipality of Bologna
}

\author{
Andrea Resca and Mauro Moruzzi
}

\subsection{Introduction}

In Italy, the introduction of the National Health Service (Servizio Sanitario Nazionale - SSN) in 1978, based on law 833/1978, provided municipalities with the opportunity to make substantial innovations in healthcare. Hospital-centred care was considered outdated. The aim was to dispense with a model based on hospital hubs on the one side and general practitioners (GPs) spread throughout the area on the other. The latter operated as gatekeepers to hospital services, and still do. The introduction of the SSN challenged a healthcare system that had developed largely independently from the characteristics of the socio-economic context. Hospitals, in alliance with the medical profession and the academic environment, determined services, or supply, that corresponded only partially to the demand from citizens and regions. The law outlined a framework for rebalancing this situation. Improving citizens' access to healthcare was an element of National Health Service reform, especially in the city of Bologna where long waiting lists, fragmented offerings and a lack of transparency characterized access to secondary care. The municipality of Bologna addressed these issues by creating booking centres supported by information technology enabling citizens to book services for secondary care. In Italy, and very probably Europe, this was the first instance of an information system connecting distributed booking offices at the city level. Since 1990, citizens have been able to use this e-booking service to access specialist ambulatory services, including visits and diagnostic activities.

\author{
A. Resca (夰) \\ LUISS Guido Carli University, Rome, Italy \\ e-mail: aresca@luiss.it \\ M. Moruzzi \\ CUP2000 s.p.a, Bologna, Italy \\ e-mail: mauro.moruzzi@cup2000.it
}


In this chapter, we analyze the origin of the e-booking service. The interpretative framework for investigating the advent of an e-booking service is provided by the concept of information infrastructure, focusing specifically on the role of the installed base (Hanseth and Lyytinen 2010; Hanseth et al. 1996). The concept of installed base includes both standing elements and systems already in place and existing institutional and organizational components (Bongsug and Lanzara 2006; Ciborra and Hanseth 2000). We study how the installed base was involved in the realization of this innovative service.

The literature suggests that the installed base can have both hindering and enabling effects on technical and institutional innovation (Lanzara 2009). The case in question represents an instance in which the existing installed base challenged the institutional and organizational innovation process. The healthcare system revealed itself as a trap from which it was difficult to escape (Lanzara 2009). In fact, a service like e-booking implied abandoning routines and practices that characterized paperbased booking. Alternative organizational arrangements had to be devised as the hospital and GP-centred model did not provide a supportive environment for this innovative form of access. Emphasis was put on the mobilization of installed base components related to political, organizational and technological resources originated outside healthcare. Our objective is to shed light on what led to innovative institutional arrangements and organizational routines and what capabilities were needed to challenge the established normative order and enable the creation of e-booking.

We begin with a brief overview of Italian healthcare. In the sections that follow we present the overall trajectory of the centralized booking system over the period 1990-2015 and subsequently present an investigation of the origins of the e-booking system. We focus on a period that starts in 1987 with the issue of the Health Plan by the municipality of Bologna and ends in 1993 when the innovative booking system went full speed. We end by presenting our analysis and discuss the mobilization of installed base resources for putting e-booking in place.

\section{Method}

This chapter is based on a longitudinal study on the evolution of an e-booking system. Following Yin (2009), this can be considered both a critical and a revelatory case study as it is, probably, the first example of a solution that supports citizens' access to healthcare in Europe and because of its capacity to develop both in scale and scope.

One of the authors had a leading role in the project and was a direct witness of its main phases, participating in meetings and boards at both the political and organizational level, with access to the related documentation. Data collection was integrated with semi-structured, in-depth interviews with the key players in the project. Twelve interviews were carried out between 2013 and 2015. Archival data were used as well as Italian publications related to this experience. 


\subsection{Italian Healthcare Overview}

The National Health Service (Servizio Sanitario Nazionale - SSN) was introduced in Italy in 1978 (law 833/1978) and replaced the previous system of state insurance that had been founded after the Second World War. The aim was to create an efficient and uniform health system covering the entire population, irrespective of income or contributions, employment or pre-existing health conditions. The SSN provides free or low-cost healthcare to all residents (including those from other EU countries) and emergency care to visitors, irrespective of their nationality.

The proposed healthcare model outlined an alternative to the previous hospitalcentred model, by creating a network of health facilities addressing the needs of the different socio-economic contexts. The aim was to create a network of health facilities able to respond to the characteristics of the different regions, which meant local government, specifically the municipalities, acquired a leading role. Healthcare based on the medical profession, academic medical science and technological development revolving around hospitals was challenged by a vision that put citizens and their living and working conditions at the centre - or, more accurately, proposed the decentralization of service provision, initiated by the establishment of local health facilities. However, results were questionable and the dwindling role of hospitals was not fully covered by the provision of appropriate continuity-of-care services as well as prevention, treatment and rehabilitation programmes. Families with members suffering from mental illnesses, chronic diseases and the non-self-sufficient elderly bore the burden of this situation (Moruzzi 2009).

Local health units (Unità Sanitaria Locale - USL) were in charge of the transformation of the healthcare model. These were local authorities and Bologna, a city with about 400,000 inhabitants, had three USLs. The national level allocated resources to regions that, in turn, supported USLs financially. Regions were also in charge of healthcare planning. However, USL management was in the hands of the municipalities. As the government level closest to citizens, they appointed USL management committees that represented local communities and spoke for them. The intention was to monitor closely healthcare provision to citizens.

At the beginning of the 1990s, this governance system went into crisis due to four main factors: the financial instability of the municipalities; the involvement of management committee members in political corruption scandals; the rise of neoliberal policies at European level during the 1980s; and the expensive and fragmented organization of healthcare services (Moruzzi 2014).

Laws 502/1992 and 517/1993 reorganized healthcare and were dubbed the "counter-reform" of law 833/1978. USLs were transformed into local state-run companies (Azienda Sanitaria Locale - ASL) and big hospitals acquired a new status, University Hospital Company (Azienda Ospedaliero Universitaria - AOU). These organizations centralized control with three leadership positions (managing director, health director, administrative director). Management committees nominated by the municipalities were ousted and the region became the appointing authority. Social health districts, led by the municipalities, were introduced to 
represent local requirements and to promote integration with social services but their influence on healthcare has been limited.

A consequence of this reform was that traditional hospital-centred healthcare, governed by the medical profession and typical of the pre-National Health Service era, did not re-emerge. However, regional and corporate bureaucracy was imposed once the USL management committees were abolished. The most significant implication of this was that it proved impossible to integrate healthcare and social assistance in accordance with the 1978 legal schedule. Finally, healthcare in Italy is still governed by regulatory structures at both regional and unit level that emphasize political and bureaucratic control rather than the development of medical activities.

\subsection{The Evolution of a Centralized Booking System: 1990-2015}

Since 22 January 1990, every citizen of the municipality of Bologna in need of a specialist appointment or a medical examination has been able to access a dedicated centre and book an appointment through an e-booking system that pools the services available at city hospitals and health centres. A number of booking centres spread across the city was one of the main objectives of the 1987 Municipal Health Plan to deal with long waiting lists and the difficulties citizens encountered in accessing health services. At the end of the first year of operation, 264,048 users contacted e-booking centres for a total of 610,498 transactions.

In the years since, the centralized booking service has developed in both scale and scope. Table 15.1 outlines the phases that have characterized this evolution.

Pharmacies became involved shortly after the inauguration of the service, due to their network presence and the possibility of offering widespread access points to healthcare. As private businesses, they were not used to collaborate with public institutions, like the municipality of Bologna, for improving healthcare. Significant resistance had to be overcome, as e-booking was not considered an appropriate service to be provided to pharmacies and related competences were not available. However, it was clear that pharmacies did have a role to play in healthcare and after an initial experimental period, the large majority joined the project, representing a solution to offering a wider range of services. However, at first (1996) booking activity was limited to restricted services and it was only after several years that the same range was made available to both pharmacies and booking centres.

In 1990, citizens living outside the boundaries of the municipality of Bologna accessed secondary healthcare using paper-based procedures supplied in each health facility. Things changed in 1999 when the centralized e-booking service was enlarged to cover the entire area. At that point, further 600,000 people, making a total of about 1 million, were able to take advantage of e-booking centres. By the second half of the 1990s, the booking system, which had been designed in a preinternet era, was considered outdated and inadequate for extending scale and scope. In 1999 a tender for its substitution was issued and the new e-booking system went 
Table 15.1 Key milestones in the evolution of the centralized booking system for health services in Bologna

\begin{tabular}{|c|c|c|}
\hline Year & Central e-booking system: scale & Central e-booking system: scope \\
\hline 1990 & $\begin{array}{l}\text { Every citizen has access to } 25 \text { e-booking } \\
\text { centres (inc. hospitals, health centres and } \\
\text { department store) throughout Bologna to } \\
\text { book specialist appointments or medical } \\
\text { examinations provided at municipal level }\end{array}$ & \\
\hline 1996 & $\begin{array}{l}\text { E-booking possible at pharmacies but only } \\
\text { some medical examinations available. } \\
\text { Number of centres reduced to } 19\end{array}$ & \\
\hline 1999 & $\begin{array}{l}\text { E-booking centres spread throughout the } \\
\text { metropolitan area (Bologna and } 50 \\
\text { municipalities in the province) }\end{array}$ & $\begin{array}{l}\text { Able to book services provided by } \\
\text { "intramoenia", accredited health } \\
\text { facilities and private healthcare }\end{array}$ \\
\hline 2000 & $\begin{array}{l}\text { The software system is substituted following } \\
\text { a competitive tender }\end{array}$ & $\begin{array}{l}\text { Call centre introduced as an additional } \\
\text { channel for booking. The range of } \\
\text { services available is limited and will } \\
\text { be extended in subsequent years }\end{array}$ \\
\hline 2003 & $\begin{array}{l}\text { Pharmacies provide the same services as } \\
\text { e-booking centres }\end{array}$ & $\begin{array}{l}\text { A website for changes and } \\
\text { cancellations to bookings launched; } \\
\text { only some services available for } \\
\text { e-booking }\end{array}$ \\
\hline 2006 & & Electronic waiting lists introduced \\
\hline 2010 & Ferrara is included in the e-booking system & \\
\hline 2012 & & $\begin{array}{l}\text { Citizens able to book services from } \\
\text { their own electronic personal health } \\
\text { record (only services not subject to GP } \\
\text { referral) }\end{array}$ \\
\hline 2013 & Launch of the regional e-booking website & \\
\hline 2014 & $\begin{array}{l}\text { Modena and Reggio Emilia included in the } \\
\text { e-booking system }\end{array}$ & $\begin{array}{l}\text { Both the e-booking website and the } \\
\text { electronic personal health record offer } \\
\text { the possibility to book services subject } \\
\text { to GP referral }\end{array}$ \\
\hline
\end{tabular}

into operation the following year. At first, the services provided were limited to the public healthcare. Later, the aim was to make available the full range of health services, including those supplied by the intramoenia (intramurale) regime (private practice confined to public facilities), accredited health facilities and private healthcare.

A call centre was established in 2000. This was an additional channel for managing appointments and medical examinations. In 2003 the booking website was launched. After this point, citizens did not need to turn to a booking centre, a pharmacy or a call centre to access healthcare. However, only changes to bookings, cancellations and a restricted number of services were made available online.

In 2006, electronic waiting lists were introduced. When a service provided by public healthcare did not meet citizens' needs, their position in these lists could be changed. This meant they were continuously monitored and were offered alternative opportunities that emerged in the meantime. The figures (2006) illustrate the extent 
of e-booking: 3,100,000 users per year; 13,000,000 operations per year; a catalogue of 1920 services available; 6600 specialists. All of this was facilitated by 136 counters in hospitals and health centres; 236 counters in pharmacies; a call centre with 28 dedicated telephone lines; and a website.

In recent years, other provinces in the Emilia Romagna region - Ferrara (2010), Modena (2014) and Reggio Emilia (2014) - have all decided to adopt the e-booking system used in Bologna. The e-booking service was a good fit with two other projects promoted by the region and central government: electronic personal health records and e-prescriptions. Since 2012, all citizens in Emilia Romagna had been able to access an electronic folder containing documents related to their care, provided by healthcare facilities and the patients themselves. The functions of the electronic personal health record included e-booking, which was limited to services not subject to GP referral, such as gynecology, ophthalmology and prevention. In 2014 e-prescriptions were also included in this category of services. In 2013 the regional booking website was launched. Due to the integration of several booking services, it was possible to have access to the entire range of services available at regional level.

\subsection{Early Stages: From Design to Deployment of an e-Booking System}

\subsubsection{Antecedents of an e-Booking System}

In the transition period that followed the introduction of the National Health Service, the new role of primary care and abandoning hospital-centred healthcare created problems in secondary care. Specifically, in the city of Bologna they resulted in long waiting lists and difficulty in accessing the range of services offered by a large number of providers. In 1987, the municipality of Bologna, in charge of the supervision of USLs, decided to formulate a Health Plan to addressing the emerging situation in consequence of unsatisfactory results related to the implementation of healthcare reform. The Health Plan had three main objectives: (1) to increase investment in diagnostic and therapeutic technologies; (2) to promote a campaign supporting health self-protection; (3) to improve citizens' access to healthcare.

The second half of the 1980s also saw the advent of informatics in the public sector. A large proportion of public administrations launched computerization plans to introduce automated procedures. Innovations, like e-booking systems, became objects of interest. In one of the city hospitals an automated registry of cancer cases was introduced, thanks to support from the University of Bologna. The collaboration between these two parties had produced a pilot of an e-booking system; it was presented to the city but without success. It was evident the project needed to scaleup to build a city-level system. So the collaboration was extended to the National Research Council and the state-owned ITALSIEL, at that time the largest software company in Italy. 


\subsubsection{Getting Ready for the Service Launch}

Unlike today, neither central nor local governments were subject to financial pressures and the Ministry of Health decided to support the e-booking project proposed by the municipality of Bologna. Project design started at the beginning of 1989 and the system was expected to be ready by the end of the year. Within a few weeks, the architecture of the database was available and software development followed. At the same time, the service catalogue was compiled. Standardizing the terminology used to describe services was a fundamental concern: hospitals and health centres had different ways of identifying a radiology examination or an abdominal ultrasound on the basis of the practices they adopted. The catalogue also standardized guidelines for patients preparing for medical examinations. A software solution, supporting the use of synonyms, facilitated agreement about service descriptions and promoted the building of the service catalogue.

In 1989 the Single Booking Centre (Centro Unificato di Prenotazione - CUP) directorate was created within the Health Department of the municipality of Bologna. This was an inter-institutional office composed of personnel from the three USLs and led by the city councillor in charge of the department. This entity governed the entire project.

The decision not to assign the management of e-booking centres to USLs meant an alternative organizational unit, external to the healthcare sector, had to be created to take charge of them. SYNWARE was established in the spring of 1989 and staff selection (about 100 employees) began a few months later. In the autumn of that year, training courses introduced the basic elements of the healthcare system and the use of the software solution, even though it was not yet ready. At the beginning of the new year, staff were assigned to the 25 centres in hospitals, health centres and one department store.

\subsubsection{Fine-Tuning the e-Booking Service}

The service was launched at the end of January 1990. From the first days of operation, activity was surprisingly regular, considering that the system was finalized just days before the launch and both patients and clerks were unfamiliar with the service. An improvement process was launched simultaneously involving all the main protagonists: the Health Department, the three USLs, ITALSIEL and SYNWARE. The Health Department, specifically the CUP directorate, led this process and a number of actions were taken.

As far as ITALSIEL was concerned, a new phase for the evolution of the system was inaugurated. At first, only a limited range of specialist visits and diagnostic activities was available. More complicated diagnostic activities began to be offered in the 2 years following the launch of the service. Booking time was another issue that had to be faced during this period. It was possible to reduce booking time from an average of 18-20 to 8-10 min thanks to the optimization of user interfaces (command line interfaces) and the introduction of software tools that facilitated the retrieval of services. 
SYNWARE was subject to continuous innovation of its organizational arrangements. At first, the position of primary contact was created in the most critical centres in the city. The primary contact was a point of reference for clerks and hospital/ health centre supervisors in case of problems raised during service provision. The introduction of this role was considered effective but insufficient and a further organizational solution was adopted. The area covered by the municipality was subdivided into five macro areas, each headed by a coordinator who played a pivotal role as the addressee of questions raised by all the centres and other actors involved in the service (Health Department, USLs, ITALSIEL). The five coordinators constituted a unit responsible for dealing with dysfunctionalities, staff assessments and technological and organizational resources to guarantee regularity of service provision. However, this solution was also considered inadequate and a primary contact was established in each centre. This supervisory role established a contact point for coordinators. A help desk was set up in each centre to deal with inaccurate prescriptions and provide information about the range of services provided.

Besides coordinating ITALSIEL and SYNWARE activities, the most delicate responsibility of the CUP directorate was negotiating with hospitals to obtain services that could be included in the e-booking system. Before the introduction of e- booking, each hospital managed the type and number of services provided to outpatients autonomously. With the advent of the e-booking project, control moved to the CUP directorate. This change involved lengthy negotiation with hospitals to increase the extent of services to be offered on the centralized booking system.

The CUP directorate also managed the updating of the service catalogue necessitated by the introduction of new services or modification of existing ones.

The launch of the service entailed another activity that was closely monitored by the CUP directorate: updating service schedules. There was a plurality of service providers (e.g. several radiology units for each health facility), so it was necessary to know the full extent of services available. Unexpected events also had to be managed. A union strike, participation in a conference or sick leave could interrupt service provision. In these cases, schedules needed to be updated, patients informed and new appointments offered.

\subsection{Analysis: The Mobilization of Installed Base Resources for the Construction of an e-Booking Service}

In this section we analyse the realization of an e-booking system in the municipality of Bologna from the installed base perspective (Hanseth and Monteiro 1997; Ciborra and Hanseth 2000). This entails looking at how an intricate web of technological and institutional resources (Bowker and Star 1999; Lanzara 2009; Star and Ruhleder 1996) was reconfigured to build this service. We focus on how political, organizational and technological resources were mobilized to move from paper-based booking in individual health facilities to a centralized e-booking system that could pool the health services available at city level. 


\subsubsection{The Mobilization of Political Resources}

Political resources had to be mobilized for coordinating, negotiating and building consensus about the e-booking project. The Health Department, represented by a city councillor, was the main protagonist and played a leadership role in both the design and realization of the project. Like a large proportion of Bologna's city council, including the mayor, the city councillor was member of the local branch of the Italian Communist Party (PCI). However, the organization of healthcare was influenced not only by a state-centric perspective, typical of communist ideology, but also by the Europe-wide 1968 social movement. The experience of barefoot doctors in China, emphasizing the importance of local medicine, occupational health and de-hospitalization, also constituted an important point of reference. Unsurprisingly, some party members distrusted the role of technology in healthcare. The e-booking project was questioned closely and the subject of articulate debate within the party. To some degree, the Health Plan issued in 1987 mirrored this debate although in due course there was a rebalancing of policies towards a more important role for technology.

Healthcare policy was debated not only among political parties and social movements but also between stakeholders, including the medical profession, medical science and research activity in general. The activity of the city councillor in the Health Department was influenced not only by his membership of the political party governing the municipality but also by his involvement in local healthcare. In fact, he was supported by two leading medical figures, both "outsiders" due to lengthy periods spent in the US, where one studied oncology and the other innovative techniques in surgery. Both were advocates of the role technology could play in healthcare and so provided support for the city councillor. The councillor himself had been a student of a leading professor at the University of Bologna who had founded a new discipline, the sociology of healthcare, establishing a school that regrouped a significant number of researchers and students. Several members of the CUP directorate had studied under him. This professor has been a central figure in Bologna's political and cultural life, a councillor for more than a decade and one of the authors of the White Paper that outlined a profound transformation of the city administration. His support helped to legitimize the city councillor's position in health management.

The strength of this support drove a new vision of healthcare for the city. The aim was citizens' empowerment through provision of a means by which they could voice their needs and be taken into account. Pursuing this aim meant establishing new citizen/healthcare relationships, involving hospitals and health centres. The mediating role of the CUP directorate exemplified this new relationship. It shook up the prevailing normative order as the roles of the medical profession and healthcare institutions were reformulated.

Technology, specifically information technology, constituted the tool for establishing this new relationship. The number of services available, their type and timing became transparent for all providers. Healthcare access was standardized and no longer subject to the idiosyncrasies of providers. Equality in service access was 
guaranteed, preventing discriminatory practices. Finally, a simplified and timesaving e-booking process was made available to citizens.

Then a conflict erupted. Head physicians at the university and Bologna's largest hospital, with the support of medical organizations, opposed the intervention of a third party in mediating access to healthcare and threatened not to adopt the new booking system just weeks before the launch of the service. They maintained that it was too expensive and that services offered would be poor quality. It was an impasse. Only the intervention of the mayor, who convened all the parties and emphasized how the project would be beneficial for the city, succeeded in overcoming it. However, opposition did not disappear completely. Five years after the inauguration of the service there was a further attempt to stop it and 25 years later there are still disagreements between medical directors and the Emilia Romagna regional authority, which is now in charge of healthcare management.

To sum up, the e-booking project saw the light of day because several streams of support flowed into the local branch of the PCI and the mayor was committed to backing it. This powerful advocacy was able to resist opposition from USL boards of medical directors and head physicians. Financial resources were at stake and subject to the approval of municipal representative bodies. With such a complex project, only a small reduction in the budget would have put its development and implementation at risk. Again, the political context prevented this eventuality.

Looking at the role played by the installed base - specifically, political resources for the realization of the e-booking project, it is clear that significant mobilization took place. Local government administrative and representative bodies, the majority party and USL top management were actively involved in both supporting and opposing the project. This is illustrated by the unusual protest from head physicians who threatened to stop the adoption of the booking system and the unorthodox meeting convened by the mayor to avert it. The traditional political arena for negotiation was abandoned or considered ineffective and new ways of building consensus were put in place involving the academic sector, which was usually external to the healthcare arena.

\subsubsection{The Mobilization of Organizational Resources}

The installed base was also involved in the mobilization of organizational resources. Several organizational arrangements were at stake in providing the operational context for e-booking. Traditional bureaucracies favoured it. Both the Health Department of the municipality of Bologna and USL, the bodies in charge of healthcare, were public bureaucracies. Each USL ran hospitals and health centres in a specific area, coordinating and monitoring the activities of GPs and paediatricians who were self-employed professionals. These public bodies were a type of in-house provider. Their mandate was to supply the medical needs of the people in their jurisdiction and as they were governed by executive committees nominated by municipalities they reflected each municipality's political bias. This is why the 
Health Department of the municipality of Bologna was in charge of the e-booking project even though it did not have the professional competences and the organizational capabilities to manage booking centres. The department's institutional mission was healthcare policy implementation on the one hand, and policy monitoring and supervision on the other. A similar lack of competences and organizational capabilities also characterized USLs. Nevertheless, USLs were used to managing paper-based booking systems and so were the natural candidates for running booking centres. Nevertheless, a different decision was made. USLs, as public bodies, were subject to restrictions in workforce management typical of the public sector of that time. The relocation of personnel from one booking office to another, or the extensive use of part-time staff to deal with peak times and long office hours (7.30 18.30), were not possible in the public sector, only in the private sector. Staff training was also necessary. The public sector was heavily unionized and lengthy negotiations would be required to reach an agreement on training and changes to tasks. There were time constraints for the project and this option was not considered feasible. Finally, the three USLs were largely independent units and the service would involve personnel coming from three distinct organizations, creating coordination problems.

At this point, the decision to establish a new company was made. Bologna could be considered the capital of the cooperative movement and a large number of cooperatives were present in sectors like catering, mass distribution, logistics, building and construction. According to the International Alliance of Cooperatives, "a co-operative is an autonomous association of persons united voluntarily to meet their common economic, social, and cultural needs and aspirations through a jointly-owned and democratically-controlled enterprise. Co-operatives are based on the values of self-help, self-responsibility, democracy, equality, equity and solidarity (ICA 1995, p. 3-4)." The new company was part of a group of cooperatives in the software sector provided with technological and organizational capabilities developed in the cooperative environment, which shared the political orientation of the municipality of Bologna at that time. Turning to the cooperative movement meant establishing a link with a large business entity in the local context and promoting specific values in order to compete, in some sense, with traditional public bureaucratic organizations such as hospitals and health centres.

Against this background, SYNWARE was formed. Its activities were supported by weekly training sessions involving top management, five coordinators and on occasion the entire staff. The training content supported, among other things, the adoption of new software, the introduction of new laboratory examinations and the management of critical issues encountered in everyday practice. The weekly sessions were the context in which organizational solutions were conceived. From the detailed analysis of practices and the direct engagement of operators, it was possible to figure out how to improve service provision. The continuous solicitation of operators created an environment favourable to open debate of continuously emerging issues. This was considered the only way to deal with the innovative nature of the service and the lack of experience of those 
involved in its operation. From the launch of the service to its full implementation, the organizational structure of SYNWARE has not changed significantly, apart from the coordination figures. It has maintained its relatively simple structure, as it was felt that introducing further organizational units would have obstructed the integration of the different components, which was the principal aim of the organization.

A couple of SYNWARE and ITALSIEL managers collaborated actively with the CUP directorate established at the Health Department and led by the city councillor responsible for healthcare. The directorate was regarded as the driver and control tower of the entire e-booking project and requests for services from SYNWARE, USLs or ITALSIEL were relayed to it. Any decision made at the directorate level was passed on to the party or parties involved, which activated their organizational structures accordingly.

A number of actions were in the direct remit of the CUP directorate. One of these was the building of the service catalogue. Even though this involved the establishment of work groups, led by an expert in a medical specialism and an expert in administrative procedures, both physicians, these groups were supervised by the directorate. Activities related to the catalogue building were mainly conducted in the first phase of the project. However, the process was reintroduced when new services were added or existing services changed. Schedule management and the monitoring and management of information about the services available required close collaboration between the directorate and hospitals and health centres. Each facility was responsible for communicating updated information about the services it offered. Building the service catalogue was a long and arduous process.

The CUP directorate was considered an alien presence in an environment that had always been controlled by medical science and its elite. The directorate struggled with leading physicians for control of health services. Taking only partial control of service provision constituted a significant change to established practice and was met with a hostile response from the medical profession. Power distance was a factor in this context. The profession dragged its feet when it was necessary to establish a dialogue with the directorate as it was not sufficiently legitimized in the healthcare environment.

With the advent of the new service, booking management changed considerably. Traditional public bureaucracies now had the room to innovate organizational arrangements, indicating that the installed base, insofar as it was related to organizational resources, was mobilized radically. When hindering effects prevailed, resources available outside the healthcare domain were mobilized in preference to resources present in hospitals and health centres. The existence of these external resources was fundamental to the project, as demonstrated by the involvement of the cooperative movement in running booking centres and the active role played by ITALSIEL and SYNWARE within the directorate. Now areas that had traditionally been run by the public sector saw the participation of private players. The establishment of the directorate itself was a clear example of this. The close partnership with USLs was supported by forms of coordination and control that differed significantly from those of typical bureaucracies. 


\subsubsection{The Mobilization of Technological Resources}

During the 1980s, a computerization scheme was launched throughout the Italian public administration system and subsequently in healthcare. However, it was not able to support the e-booking system and developers had recourse to resources external to the healthcare domain - ultimately the largest Italian software company of the time became involved. Only companies of that size and experience had to capability to build systems on this scale. ITALSIEL, with branches throughout the country, had been the software provider for the whole public sector and the Italian banking system, which was largely controlled by the state at that time. Informatica Friuli Venezia Giulia (IFVG), one of these branches, developed software solutions for healthcare and was involved in designing the architecture of the centralized booking system. Two solutions were proposed by the IFVG top management, one based on the ORACLE database and the other on the dBase database. The possibility of using a product like ORACLE Forms to create screens to interact with the ORACLE database sealed the decision to select the former, which was perceived as more stable and performative. The Ministry of Health approved the solution other than the Health Department coordinated by the National Research Council and the University of Bologna. The system was expected to extend throughout the country once adopted by an important city like Bologna. Being a so-called prime mover in this business would create the conditions to achieve a competitive advantage over other software providers.

Given the size and the innovative functions of the project, the architecture proposed by IFVG was evaluated at ITALSIEL headquarters in Rome. The adoption of the ORACLE database was confirmed but not the software designed to interact with it and the COBOL programming language was selected instead. Back in the 1980s, all large projects turned to this language as it provided the most robust solutions in high complex cases. While IFVG did not fully agree with this decision, on the grounds that other and more innovative solutions could have been found, the decision was considered rational for a number of reasons. First, there were time constraints. The centralized booking system had to be deployable within 6 months and there were not sufficient competences related to specific programming languages for ORACLE databases at IFVG or ITALSIEL headquarters. Second, a large number of COBOL software components that could interact with an ORACLE database were available. The challenge was to group them together to provide interfaces connecting the database and related functions. Finally, the system performance achieved was judged satisfactory, due to the experience acquired in the COBOL environment.

Going live with the e-booking service heralded a new phase in the evolution of the system, as it was necessary to accommodate the needs of nationwide health facilities that required new services or existing services to be reformulated. The aim was to offer the most complicated diagnostic activities - those involving multiple operators and sequential steps - in the 2 years following the launch of the service. The role of staff at booking centres was fundamental to a well functioning system. At the time, automated booking processes were limited and skilled staff with 
expertise in using the system played a decisive role in providing an appropriate service. Another issue was GPs' handwriting: a statistical analysis of those whose prescriptions were most often rejected by operators due to their illegibility was introduced.

The identification of citizens at booking centres was enabled by a magnetic card containing personal details. Delivering a novel tool to more than 400,000 inhabitants of Bologna carried a high risk of its misuse. However, at that time polling cards were delivered to households by traffic police officers (municipal employees) and in 1990 local elections were held. The e-booking cards were delivered along with polling cards by the police, who emphasized their importance and how they were to be used. The card soon became a symbol of an innovative solution for accessing healthcare through digital technology.

The partnership with ITALSIEL confirmed the importance of the installed base in terms of technological resources. Adoption of the COBOL programming language was contingent on the presence of existing software components that were mobilized to interact with the ORACLE database. Finally, the mobilization of technological resources was necessary for the introduction of the magnetic identification card and the role of the police determined its correct use.

\subsection{Discussion}

The origins of the e-booking system raises questions about the role of the installed base and its constraining and enabling effects. A healthcare model characterized by a polarization between hospitals on the one hand, and GPs on the other did not provide a supportive environment for creating innovative solutions to accessing healthcare. Hospitals and health centres conceived as professional bureaucracies (Mintzberg 1979; Lam 2000) operate according to standardized and bureaucratic methods of coordination and control in a context where individual expertise and professional bodies both held relevant roles. Even though routines and practices are governed by protocol, personal judgement and peer consultation were important in these organizations. Within professional bureaucracies, such as universities, schools, hospitals and courts, supervision and control are assigned not only to hierarchical superiors but also to external professional associations. These establish regulations and guidelines and are the custodians of the profession, determining appropriate and non-appropriate behaviours. It is understandable that the introduction of an innovative, IT-based system of access to healthcare would meet opposition within a healthcare model governed by professional bureaucracies and medical associations.

It was necessary to mobilize political, organizational and technological resources that could counter this situation. Political activity led the way in coordination, negotiation and building consensus. The municipality of Bologna and the Health Department were conscious of citizens' dissatisfaction with the long waiting lists, lack of transparency and inconvenience of accessing healthcare and formulated a response. 
How was the mobilization of political, organizational and technological resources demonstrated? The role played by IT was decisive here. Information technology was conceived as the driver for delineating new ways of accessing healthcare. An innovative scenario for improving healthcare services was established and contrasted sharply with existing ones. Turning to IT inevitably implied an openness towards innovation and continuous updating of implemented solutions.

The constitution of a third party able to mediate between citizens and healthcare providers represented a further aspect of the mobilization process. The CUP directorate supported by SYNWARE provided the e-booking service, eliminating professional bureaucracies such as hospitals and health centres. The service provided by these bureaucracies was substituted by organizational arrangements within the socio-economic context of the Bologna area and exemplified by the cooperative movement.

The leading role of the Health Department and the CUP directorate contributed to the legitimization of service provision outside the healthcare sphere. It was demonstrated that alternative forms of service organization could replace established ones. Traditional healthcare responsibilities, such as service bookings, shifted to an entity supervised by the Health Department and subsequently by representatives of social and political movements. Citizen empowerment was an additional aim.

Finally, the opposition of vested interests, represented by medical associations and head physicians practicing in hospitals, was overcome due to the supporting role played by the local section of the Italian Communist Party and civil society in general. The figure of the mayor was emblematic here. His authority and the consensus he acquired in the city enabled the introduction of e-booking in healthcare.

\section{References}

Bowker GC, Star SL. Sorting things out: classification and its consequences. Cambridge, MA: MIT Press; 1999.

Chae B, Lanzara GF. Self-destructive dynamics in large-scale technochange and some ways of counteracting it. Inf Technol People. 2006;19(1):74-97.

Ciborra C, Hanseth O. Introduction. In: Ciborra C, editor. From control to drift: the dynamics of corporate information infrastructures. Oxford: Oxford University Press; 2000. p. 1-15.

Hanseth O, Lyytinen K. Design theory for dynamic complexity in information infrastructures: the case of building internet. J Inf Technol. 2010;25(1):1-19.

Hanseth $\mathrm{O}$, Monteiro E. Inscribing behaviour in information infrastructure standards. Account Manag Inf Technol. 1997;7(4):183-211.

Hanseth O, Monteiro E, Hatling M. Developing information infrastructure: the tension between standardization and flexibility. Sci Technol Hum Values. 1996;21(4):407-26.

ICA. Cooperative principles for the 21st century: introduction. Rev Int Co-Operation. 1995;88(3):3-4.

Lam A. Tacit knowledge, organizational learning and societal institutions: an integrated framework. Organ Stud. 2000;21(3):487-513.

Lanzara GF. Building digital institutions: ICT and the rise of assemblages in government. In: Contini F, Lanzara GF, editors. ICT and innovation in the public sector. Houndmills: Palgrave MacMillan; 2009. p. 269-96. 
Mintzberg H. The professional bureaucracy. Organization and governance in higher education. 1979. p. 50-70.

Moruzzi M. e-Health e fascicolo sanitario elettronico. Milan: Gruppo 24 Ore; 2009.

Moruzzi M. La sanità dematerializzita e il fascicolo sanitario elettronico. Roma: Il Pensiero Scientifico Editore; 2014.

Star SL, Ruhleder K. Steps toward an ecology of infrastructure: design and access for large information spaces. Inf Syst Res. 1996;7(1):111-34.

Yin R. Case study research: design and methods. Thousand Oaks: Sage; 2009.

Open Access This chapter is distributed under the terms of the Creative Commons AttributionNonCommercial 2.5 International License (http://creativecommons.org/licenses/by-nc/2.5/), which permits any noncommercial use, duplication, adaptation, distribution and reproduction in any medium or format, as long as you give appropriate credit to the original author(s) and the source, provide a link to the Creative Commons license and indicate if changes were made.

The images or other third party material in this chapter are included in the chapter's Creative Commons license, unless indicated otherwise in a credit line to the material. If material is not included in the chapter's Creative Commons license and your intended use is not permitted by statutory regulation or exceeds the permitted use, you will need to obtain permission directly from the copyright holder.

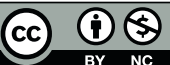

